\title{
Imagens a fabular ambientes: desejos, perambulações, fugas, convites
}

\author{
Elenise Cristina Pires de Andrade ${ }^{1}$ \\ Érica Speglich ${ }^{2}$
}

RESUMO - Este texto deseja uma escrita-pesquisa em experimentação, ressoando com o conceito de fabulação de Deleuze e $(\mathrm{m})$ imagens que se propõem em exploração de sentidos para pensar uma outra educação, um outro ambiente. Desejar sem ser falta. Maquinaria de desterritorialização. Escolher cartas como movimentadoras de pensamento para ampliar as possibilidades argumentativas e desprendê-las da representação, pretendendo a força e a intensidade da expressão, marcando uma postura política de escrita-pensamento-pesquisa para as imagens e(m) questões ambientais. Perambular por elas e potencializar as ideias de potência e força de criação no desaparecimento da distinção entre verdadeiro e falso. Fugas. Interessa-nos a criação e o que se extrai desse fabular, as potências sem necessidade de efetuação, um potente vir a ser que permanece em potência de ser. Imagens que nos levam a extremos: invisível, indizível, impensável. Intervalo do qual podem emergir movimentos para o pensamento. Cartas caóticas que viajam, convidam. Convites à inseparabilidade entre arte e vida.

Palavras-chave: Imagens. Fabulação. Arte. Vida.

ABSTRACT - This article desires an inquiry-writing on experimentation, resounding with Deleuze's concept of fabulation and/in images that are proposed to explore senses to think about another education, another environment. Desiring without missing anything. Deterritorialization machinery. Choosing letters as movements of thought to enlarge possibilities of argumentation and disengage them from representation, aiming for the strength and intensity of expression, marking a political stance of writing-thought-research for images and/on environmental issues. Roaming through images and ideas to leverage the power and creative force in the disappearance of the distinction between true and false. Flights. We are interested in these creative forces of the fabulation process. Intensities with no need to be actualized, a powerful becoming that remains in the power of being. Images that take us to the extreme: invisible, unspeakable and unthinkable. A gap where movements of

\footnotetext{
${ }^{1}$ Professora da UEFS. nisebara@gmail.com

${ }^{2}$ Professora da Faculdade de Administração e Artes de Limeira. speglich@gmail.com
} 
thought can emerge. Chaotic letters that travel and invite. Invitations to the inseparability between art and life.

Keywords: Images. Fabulation. Art. Life.

\section{Desejos}

A cidade não é um lugar. É a moldura de uma vida. A moldura à procura do retrato, é isso que eu vejo quando revisito meu lugar de nascimento. Não são ruas, não são casas. O que revejo é um tempo, o que escuto é a fala desse tempo. (COUTO, 2005, p.

145)

Desejar uma moldura para uma imagem/retrato sem preencher o vazio, experimentando a visão do que se sente e escutando o que não é falado. A proposta deste texto deseja. Imagens que se propõem em exploração de sentidos para pensar uma outra educação, um outro ambiente, ressonâncias em cartas, talvez. Cartas que desejam explorar notícias, inventar ideias, expor sentimentos, ex-pressões. Cartas como uma aposta estética de exploração de pensamentos, conhecimentos, experiências, vidas $\mathrm{e}(\mathrm{m})$ ambientes singulares. Não uma metáfora "escrever como se escreve uma carta", mas uma singularização expressa. Afirmação de uma afinidade entre pensamento e vida

[...] que lança na direção da experimentação e da invenção de si mesmo e do mundo - uma vida artista - um pensamento capaz de afirmar o artifício como potência da vida e que, portanto, não só já não reconhece os limites entre arte e vida como também desfaz as fronteiras que separam a vida e o conhecimento de uma atividade criadora (GODOY, 2008, p. 122).

Desejar o esfacelamento dessas fronteiras em uma escrita-pesquisa entre lugares. Cartas à deriva como potência de expressão para pensamentos acerca da educação e ambiente e questões ambientais em uma escrita que se experimenta estar entre caminhos. Nem em um lugar nem em outro. Grafias que expressam, às vezes sem pressa, às vezes quase ao vivo. Invencionices.

Desejar sem ser falta. Antes, desejar como uma maquinaria de desterritorialização, nos dizem Deleuze e Guattari (1977). Funcionamento como afirmação de experimentação, roubando potências de Godoy (2008) ao apresentar o movimento da ecologia menor sendo escrita e marcada nas folhas de papel de seu livro. "[...] uma outra forma de relação com o mundo e as coisas, não afeita às uniformidades e aos enquadramentos pressupostos pela ecologia maior" (GODOY, 2008, p. 27). Assim como propõe a pesquisadora, queremos desabituar-nos das uniformidades e dos enquadramentos pressupostos por uma grande quantidade de pesquisas que se debruçam sobre as imagens ou mesmo com elas. 
Desejar a busca por escritas-pesquisas que pretendam considerar as potências das imagens de não representar a realidade, de não equivaler a conhecimentos concretos, de não remeter a significados estabelecidos a priori. Pesquisas que pretendem uma soltura das imagens em perambulações por nonsenses, por vontades de expressão. "A imagem dogmática, que remete às verdades incontestáveis e inabaláveis, é sempre o pensado do pensamento [...]" (GODOY, 2008 , p. 123). Não querer pensamentos já pensados, mas potências de vir a ser (ou não) movimentado pelo pensamento. Singularizar o (im)possível. Fabular ambientes. Cartas que se jogam ao mundo na pretensão de pensar o impensado.

Carta era uma coisa séria, comprometedora, mesmo. Cena clássica nos filmes de outrora: o marido está mexendo nas coisas da mulher recentemente falecida e dá com um maço de cartas, cuidadosamente amarradas com uma fita (essa fita é indispensável). Mãos trêmulas, desfaz o laço, começa a ler ansiosamente e descobre que a mulher teve um caso. Claro que tal revelação poderia ocorrer através da Internet, mas esta sempre pode ser desmentida - não existe o problema da denunciadora caligrafia.

Há outros dramas. As cartas que não são entregues. As cartas que chegam tarde demais. E, a mais patética de todas, a carta do náufrago, enfiada numa garrafa e jogada ao mar, entregue portanto aos caprichos do destino (e das correntes marítimas) (SCLIAR, 2003, s/p.).

\section{Cartas no intervalo: convites}

Do outono de 2010.

Prezados/as leitores/as

É chegada a nossa hora de escrever. Nós, imagens, deixamos aqui um breve convite ao devaneio. Não representamos nada. Esqueçam as narrativas sobre o consumo, o des-consumo, o inconsumível.

Percam-se no poente, nas luzes cor de laranja que envolvem as maçãs do rosto e escondem os olhares curiosos que fitam o inusitado.

Mergulhem no choque de cores e texturas que não explicam e fazem com que o incompreensível pule. E continue incompreensível. Porém, sentido. Expresso.

Subam nas estruturas e sintam o cheiro que não exala, o suor que não escorre e a poeira que não levanta. Porém, visíveis. Sentidos.

Caminhe por entre os montes e toque os pássaros que teimam em aparecer. Porém, brancos.

Palavras não ditas continuarão a vagar quando a noite chegar. Porém.

Atenciosamente, 


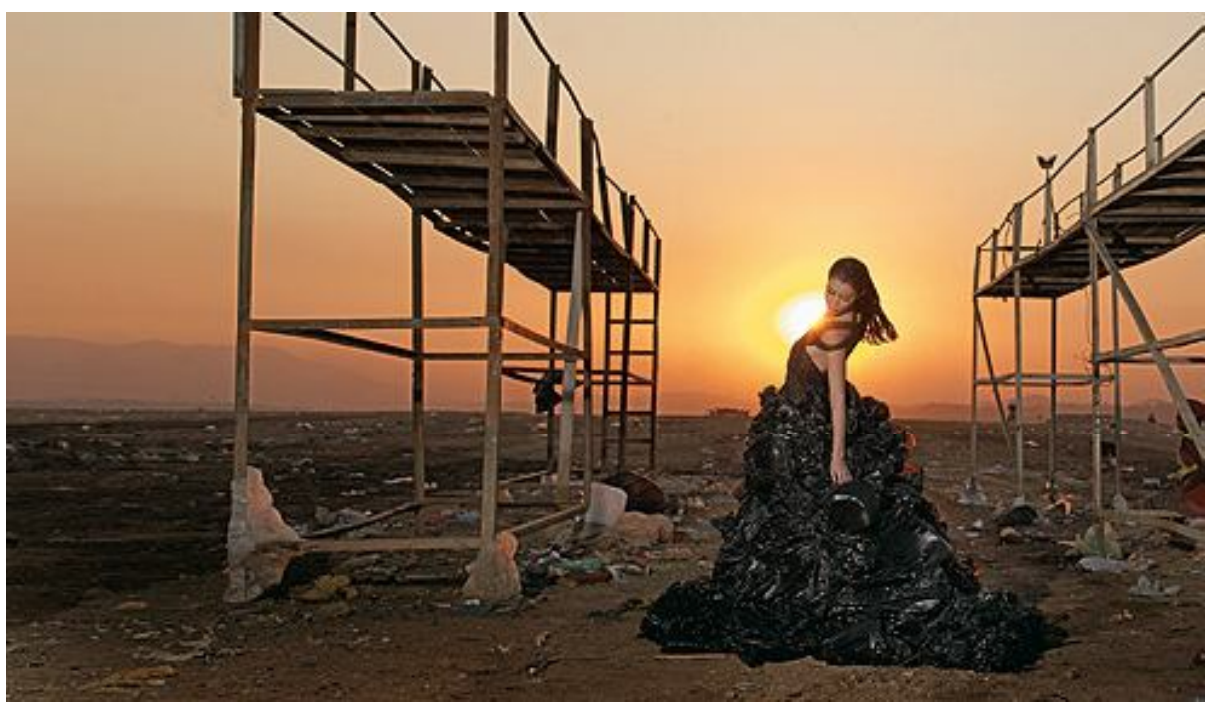

Figura 1 - Corpete trançado de câmara de pneu e saia feita com mil sacos de lixo reciclados, ambos da série LuXDELIX, de Jum Nakao.

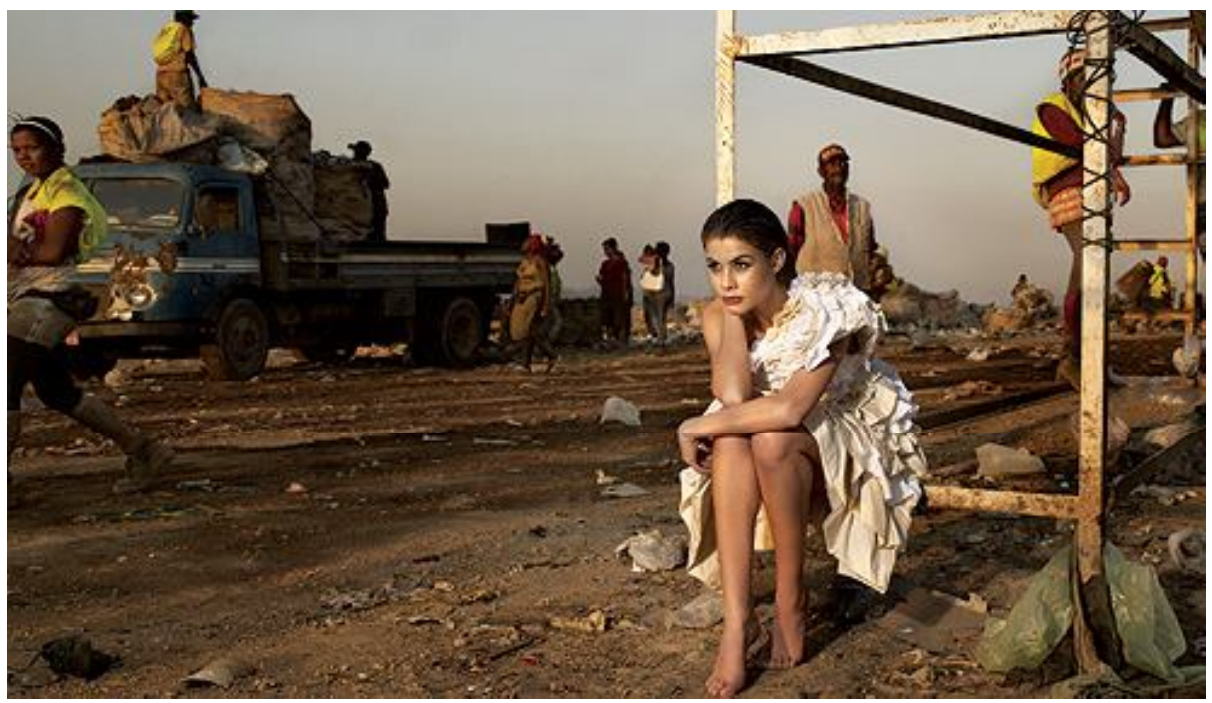

Figura 2 - Vestido tipo dobradura de Luiz Claudio Silva, feito de algodão orgânico tingido com chá. 


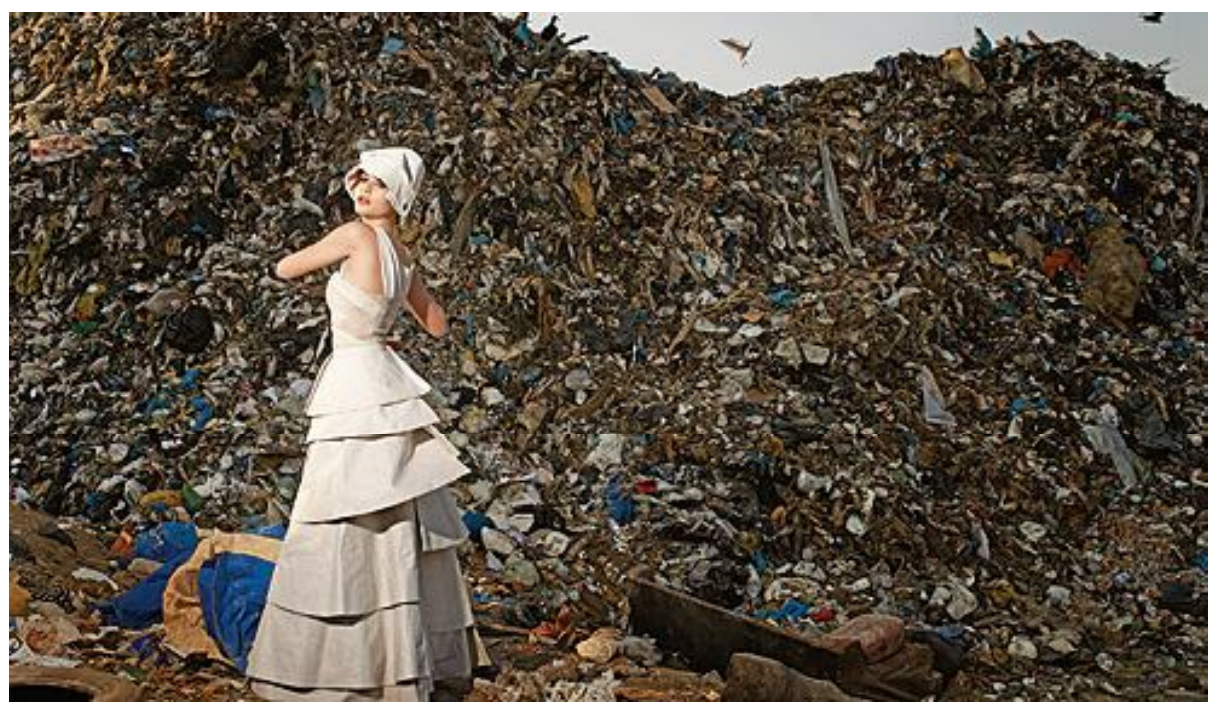

Figura 3 - Look Osklen Collection.

Figuras 1, 2 e 3 - Fotos: Cláudio Capri; moda: Denise Dahdah; produção executiva: Ricardo Oliveros; assistente de produção: Bruna Lobo; maquiagem: Cecília Macedo (GLLOSS). Revista QUEM, ed. 369, 03 de outubro de 2007. Disponível em: http://revistaquem.globo.com/Quem/0\%2C6993\%2CEQG1644247-6129\%2C00.html . Acesso em $23 /$ jun/2011.

Desejar na provocação com Sousa Dias (2007) ao pensar, com Deleuze, nos movimentos de fabulação na escrita literária:

E que interesse teria escrever sobre o amor, escrever o amor, romance ou poema, se não fosse para atingir o Amor como estado já não humano, quer dizer, tal como jamais foi, não é nem será vivido: o Amor que já não é o de uma experiência pessoal, que já não é o de ninguém, Afecto puro (SOUZA DIAS, 2007, p. 281).

Interessam-nos, para este texto, os movimentos da fabulação ao buscarmos os limites, as margens, os extremos. Essa abertura fabulada de afetos puros, no extremo. E suas provações de intervalos, fissuras, rachaduras: no pensamento, na escrita, na pesquisa, na vida.

Desejar deslocar essas ideias para pensarmos em imagens, ambientes e educação ambiental. Encontros que só podem ser sentidos, que agitam a alma abrindo-a para o impensável, o imemorial, o insensível. Convites de cartas. Afetos puros, no extremo.

\section{Perambulações}

Perambular pelas imagens. Cartas como movimentadoras de nosso pensamento para ampliarmos as possibilidades argumentativas e desprendê-las 
do movimento da representação, pretendendo a força e a intensidade da expressão, marcando uma postura política de escrita-pensamento-pesquisa para as imagens $\mathrm{e}(\mathrm{m})$ questões ambientais. Para isso, pretendemos, junto a alguns/mas pesquisadores/as, filósofos/as, artistas, inspirar encontros “[...] que possibilitam uma perplexidade da alma, que forçam a pensar o impensável, a lembrar o imemorial e a sentir o insensível" (SPEGLICH, 2009, p. 102). Cartas que não necessariamente precisem ser escritas e marcadas neste texto, mas sim potência de ampliação do pensamento. Desejos em devir mergulhando por "[...] desvios, desvãos, vãos, distorção, deslizes pela superfície das imagens e apostando na ideia de que imagens co-criam mundos sem equivalentes, embaralhando supostas determinações" (ANDRADE; SPEGLICH, 2008, p. 14).

Um conceito que temos tentado movimentar a partir do pensamento de Gilles Deleuze, a fabulação nos remete às ideias de potência e força de criação no desaparecimento da distinção entre o verdadeiro e o falso. Fabulação que remete, também, à instalação de um devir. Propomo-nos a pensar na fabulação como forma de sair do e fazer fugir $o$ jogo das imagens representacionais, que fixam o movimento do conhecimento, do pensamento e da vida submetendo-os à linearidade do tempo cronológico.

Ao pensarmos em questões relativas à educação ambiental no campo educacional, nos deparamos frequentemente com determinações de "certos" e "errados" na forma de lidar, estar, viver, entender o mundo. Um mundo dado. Ambientes que poderíamos apenas conhecer entre narrativas e demarcações conceituais. Propostas de que seriam apenas nessas formas predeterminadas de relação com o mundo que se estabeleceriam as possibilidades de cuidar da vida, em todas as suas formas. Mais ainda, de conceituar a vida e o ambiente para poderem, a partir dessa classificação e territorialização, ser conservados e mantidos. Acompanhar Palharini (2007) quando propõe, para (im)possibilidades de uma educação ambiental, que a educação não seja considerada um território fechado, mas antes uma "terra de ninguém" e, consequentemente, continua a autora em companhia de Silvio Gallo, "[...] uma terra de todos, um território aberto e instável” (GALLO, 2007, p. 32).

Instabilidade a nos instigar - e estendemos o convite aos/às leitores/as (n)a vontade de criar e (n)o entendimento de que seria na instalação da possibilidade de devir que se instalaria a possibilidade de vida, e não em uma linearidade representacional que a ligaria "simplesmente" ao conceito de vida. Devir que se instala e perambula entre escrita e pesquisa, de(vir) escrever e pesquisar junto às reticências. Ambiente que se inventa nesse movimento desejante que salta e mergulha através das imagens. Variadas formas de viver em relação. Nossa proposta, então, seria levar esse pensamento à radicalidade para instigar, no extremo, a criação de um intervalo, de uma fissura, de uma rachadura. E, com isso, a possibilidade de nos instalarmos, em devir. Desejos. Convites à inseparabilidade entre arte e vida. 


\section{Fugas}

Estou aqui, em Arari, Nova Iorque, estou aqui ou do Chuí ao Oiapoque ${ }^{3}$. Vamos fugir desse lugar, baby ${ }^{4}$.

Fugir de onde, de que lugar, se Zeca Baleiro nos encanta com essas (im)possibilidades demarcatórias? Se não sabemos onde estamos, para onde fugir? Mesmo sabendo que Arari é uma cidade no interior do Maranhão onde viviam os pais de Zeca, juntamente com os demais filhos do casal ${ }^{5}$, será que teríamos mesmo essa fixação do ambiente arariense? Ou poderíamos nos perder e nos achar sem nunca termos achado/perdido Arari e, nessa angústia do não lugar, da inexistência de uma cidade de origem, como nos avisa Mia Couto na epígrafe deste texto, deixar-nos transpassar pela fabulação de ambientes pelas imagens?

Ilhas ou aglomerado de lixo e lama? Não seria esse o ponto abordado pelas nossas perambulações em produção de linhas de fugas, mas a potência da subversão criada na invenção da imagem - ilhas não costumam desaparecer sem serem notadas! Por que não falar de um ambiente fabulado pelos movimentos do mundo, no mundo, nas imagens, entre imagens, que estariam aquém e além das topologias fixadoras dos conceitos representacionais?

[...] entre as imagens no sentido muito geral e sempre particular dessa expressão. Flutuando entre dois fotogramas, assim como entre duas telas, entre duas espessuras de matéria, assim como entre duas velocidades, ele é pouco localizável: é a variação e a própria dispersão (BELLOUR, 1990, p. 14).

Dispersão de fixações. Movimentos por outros pensamentos para a educação ambiental em fugas pelas frestas, criativamente em fabulações e proliferações de ambientes, ciências, mundos, sentidos. Assumir que não é apenas a linearidade de uma suposta realidade-ficção que movimentaria e possibilitaria a produção de conhecimento mas também (im)possíveis transgressões: uma aluna me contou que ouviu o seguinte comentário de uma adolescente ao se deparar com uma lagoa povoada por inúmeras espécies de peixes: "Nossa, parece um aquário!". Por que não se permitir fabular junto ao pensamento da adolescente para que não mais tenhamos a lagoa ou o aquário como "original", mas adensamentos de espaços-tempos?

"Imagem-intensidade", um ato de criação que não é privilégio da arte, mas parte de toda uma série de invenções, de unções, de blocos de duração, blocos de movimento, invenções de conceito, etc., séries que têm em

3 Verso da música Musak (1999), composta por Zeca Baleiro.

4 Verso da música V amos fugir (1984), composta por Gilberto Gil e Liminha.

5 Informações coletadas no site oficial do artista, disponível em < http://www2.uol.com.br/zecabaleiro/>, na seção de textos "Bala na agulha", texto “Musak - out. 2005”. Acesso em: 23 jun. 2011. 
comum, como lugares de criação, a constituição de espaços-tempo (FURTADO, 2007, p. 48).

Uma proposta de pensar entre as imagens a partir de algumas apostas e de algumas fugas [...]. Aposta no conceito de imagens como superfícies do acontecimento; imagens que nos afetam, que nos deslocam e sentidos produzidos neste contato deslizante, efêmero. Fugas de ideias como a onipotência da analogia fotográfica, o realismo da representação, o regime de crença na narrativa e a concretude da realidade. Aposta em imagens que se movimentam e existem por si, que explodem em sentidos. Aposta no entre, nas rachaduras provocadas por este/neste entre lugar, ou entre tempo (SPEGLICH, 2009, p. 103).

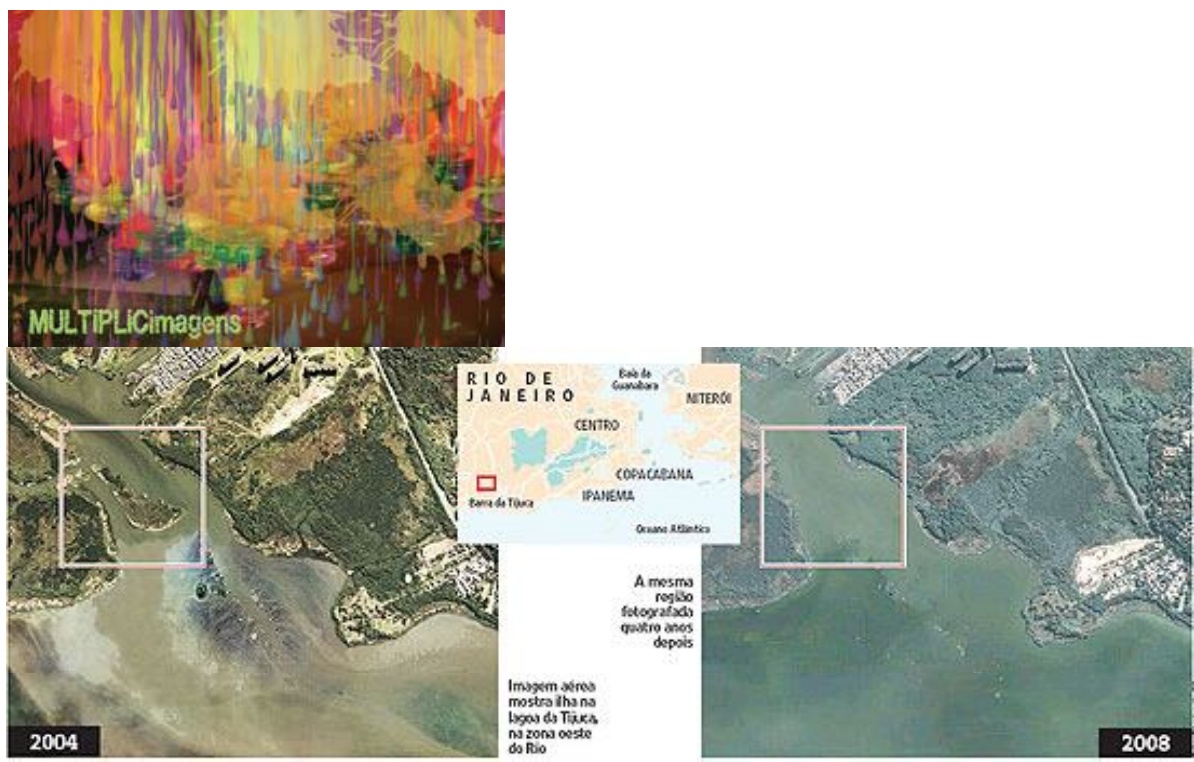

Figura 4 - O sumiço de uma ilha com cerca de 20 mil metros quadrados na lagoa da Tijuca, na Barra da Tijuca (zona oeste do Rio), intriga ambientalistas e integrantes do governo do Estado do Rio. Fotos aéreas de 2004 comprovam a existência da ilha, que desapareceu segundo as imagens feitas em 2008.

(...) "O problema não é o sumiço da ilha, praticamente um amontoado de lama", diz o biólogo Mário Moscatelli. "O que impressiona é que o governo ainda tenha dúvidas sobre o projeto. A dragagem da ilha levou meses, deve haver um registro disso", afirma. Para ele, a retirada da ilha não representa perda ambiental considerável, mas é preciso retomar a limpeza da lagoa. "Ainda existem 6 milhões de metros cúbicos de lama e lixo ali", diz.

Fonte: Folha Online, 17/03/2009: http://www1.folha.uol.com.br/folha/cotidiano/ult95u535898.shtml

Fabular... Se as fábulas levam a um final, preferencialmente cheio de lições a se ter e caminhos certos a se seguir, a ideia de fabular (com Deleuze) desloca-se para uma não fábula. Sem final, sem lições, sem caminho a seguir. Também não uma novela, na qual algo se passou (DELEUZE; GUATTARI, 1996, p. 63), mas produção de fugas, apostas em encontros. 
Nada passará pela lembrança, tudo aconteceu nas linhas, entre as linhas, no E que os torna imperceptíveis, um $e$ outro, nem disjunção nem conjunção, mas linha de fuga que não pára mais de se traçar, para uma nova aceitação, o contrário de uma renúncia ou de uma resignação, uma nova felicidade? (DELEUZE; GUATTARI, 1996, p. 81).

Sílvia de Paiva, ao analisar a obra do cineasta iraniano Abbas Kiarostami, nos diz: "É importante notar que, no processo de fabulação, conceitos como verdade e mentira entram em suspensão" (PAIVA, 2008, p. 7). O que se conta, o que se mostra não tem ligação direta com algo vivido, existente, localizável - espacial e temporalmente. Interessa a criação e o que se extrai desse fabular, interessam as potências e as possibilidades de vir a ser, sem a necessidade de efetuação. Deslocamo-nos, assim, de um tempo cronológico e suas amarras, das ideias de lembrança e de origem, deslocamentos que desejamos para nossos pensamentos, como explicitamos no início deste texto.

Deslocamentos e adensamentos como sugeriu o técnico do time de futebol inglês Arsène Wenger depois que seu time perdeu de quatro a zero para o Barcelona - pela Copa dos Campeões, temporada 2009/2010 -, os quatro gols marcados por Lionel Messi, jogador argentino que, segundo as falas de um aturdido técnico, se parecia com um jogador de videogame. O encanto e a imprevisibilidade do Messi "humano" foram tão intensos que ele virou avatar dele mesmo no videogame ${ }^{6}$. Pura fabulação?

Imagens que fabulam ambientes, provocando pensamentos, escritas, pesquisas, educações, vidas vinculadas a seus limites e suas margens. Fabular em intensidade, levando as faculdades ao seu extremo e provocando a possibilidade de nos instalarmos em devir. Em um potente vir a ser que não se liga nem a lembranças, nem ao vivido, nem ao que se viverá, que permanece em potência de ser, pois

[...] quando o hábito e a memória submetem a casa e o território, como se estes pudessem existir independentemente do animal que os recorta, não é a arte que se torna impossível - pois ela é neste momento o consolo tão almejado -, é a vida mesma que adoece do medo de viver (GODOY, 2008, p. 265).

Que vidas e que ambientes poder-se-iam inventar nessas potências em devir? Que vidas e ambientes perder-se-iam da invenção na castração dos limites das assunções de verdades e representações? Que educação ambiental se inventaria nesses (des)encontros?

A partir de nossos desejos e de nossas perambulações, gostaríamos de aqui apresentar possibilidades de produção em linhas de fuga do escape identitário na busca por outros mundos que não o da representação, da comparação em equivalências, da necessidade de desvelar um significado a priori das imagens.

\footnotetext{
${ }^{6}$ A matéria referida encontra-se disponível em:

<http://esporte.uol.com.br/futebol/campeonatos/liga-dos-campeoes/ultimasnoticias/2010/04/06/tecnico-do-arsenal-chama-messi-de-jogador-de-playstation.jhtm>. Acesso em: 23 jun. 2011.
} 
O Seminário Multiplicimagens ${ }^{7}$, por exemplo, propôs outros olhares, ouvidos, peles junto a professores/as e alunos/as, se constituindo no segundo workshop do Projeto "Educação, Ciências e Culturas: territórios em fronteiras do Programa Biota-Fapesp"8, reunindo pesquisadoras e pesquisadores dessa investigação e convidadas/os. "A proposta é conversar e expandir sentidos das experiências. Todas as atividades ocorrerão nas escolas públicas em que trabalham as professoras e o professor de Biologia que participam do projeto Multiplicimagens", nos diz o fôlder do evento. Poderíamos, então, chamar tal expansão de cartografia de ambientes fabulados?

Na efemeridade das experiências, o fragmento irrompe a unidade, a picada
movimenta a realidade. No encontro com o instante e a duração de imagens
de natureza, professoras e professores, estudantes e conhecimentos escolares
entram nos fluxos das (des)figurações. Expressar a escola, margem sem voz,
corpo sem centro, pensamento que resiste na invisibilidade: composição de
uma frágil sobrevivência? (AMORIM, 2008, s/p).

No texto intitulado "Percepção ambiental é povoada de imagens-clichê", Susana Dias9 continua a nos movimentar por entre imagens, clichês e as pesquisas desenvolvidas por Antonio Carlos Rodrigues de Amorim, professor da Faculdade de Educação (FE) da Unicamp. Durante suas aulas com estudantes da graduação que desenvolviam trabalhos audiovisuais, o professor percebeu que:

[...] os alunos não conseguiam ver as imagens fora de determinados sentidos. Não havia um trabalho de detalhamento da imagem, de explorar as potencialidades e limitações das imagens. Não parecia ser na imagem, ou na tensão com as imagens, que os sentidos poderiam proliferar. Estamos aprendendo a encher as imagens com as coisas do mundo sem pensar a própria imagem repleta de clichês (AMORIM apud DIAS, 2009, s/p).

Susana Dias prossegue a reportagem afirmando que "reconhecer as potencialidades do clichê como um limite intenso do sentido, cujo excesso é

7 O Seminário MULTIPLICimagens ocorreu nos dias 28/11, 4 e 5/12/2008 em três escolas da rede pública de Campinas, São Paulo, e foi organizado pelo Projeto de Pesquisa "Educação, Ciências e Culturas: territórios em fronteiras no Programa BiotaFapesp" e Grupo de Estudos 'Humor Aquoso', FE/UNICAMP.

8 "Educação, Ciências e Cultura: territórios em fronteiras", realizado junto ao Programa de Pesquisas em Caracterização, Conservação e Uso Sustentável da Biodiversidade do Estado de São Paulo, financiado pela Fundação de Amparo à Pesquisa do Estado de São Paulo (Biota/Fapesp), é coordenado pelo professor Dr. Antonio Carlos Rodrigues de Amorim, da Faculdade de Educação da Unicamp. Para Amorim, priorizar ações dentro das escolas "permite que a escola tenha dentro dela algo que não seja tão escolar, que não exige explicação". O trecho citado foi extraído do texto "A natureza ex-posta: imagens que duram", de Susana Dias, publicado em 12 de dezembro de 2008. Disponível em: <http://www. labjor.unicamp.br/midiaciencia/article.php3?id_article=661> Acesso em: 23 jun. 2011.

9 Artigo publicado em 10 de fevereiro de 2009 através do Laboratório de Estudos Avançados em Jornalismo da Unicamp. Disponível em: <http://www.labjor.unicamp. br/midiaciencia/noticias.php3?id_article $=666>$. Acesso em: 23/06/2011. 
plano de forças para o vazio, é a argumentação principal do pesquisador na análise das imagens" (DIAS, 2009, s/p).

Forças para o vazio, des-identidades em imagens de ambientes que abrem fissuras no círculo concêntrico da espiral da significação. "O que isso significa?" Aquilo. "E o que aquilo significa?" Aquele outro. E assim seguindo em uma infinita cadeia interligada de comparações e equivalências - o que, de acordo com Deleuze (2003), aponta o modelo platônico de mundo. O Seminário Multiplicimagens também pretendeu romper com essa cadeia fixadora de sentidos das imagens. Cadeia fixadora que, ao se quebrar, faz proliferar as potências de criação e instala a possibilidade de devir: imagens que passam a poder fabular. Fabular mundos, pensamentos, ambientes. Fugas como as cavoucadas por alunos e alunas ${ }^{10}$ da professora de Biologia e Educação Ambiental Ionara Urrutia Moura, do Colégio Técnico de Campinas (Cotuca), quando produziram vídeos numa aposta em "esvaziar as imagens dos clichês", como nos disse Amorim na reportagem, já citada, de Susana Dias ${ }^{11}$.

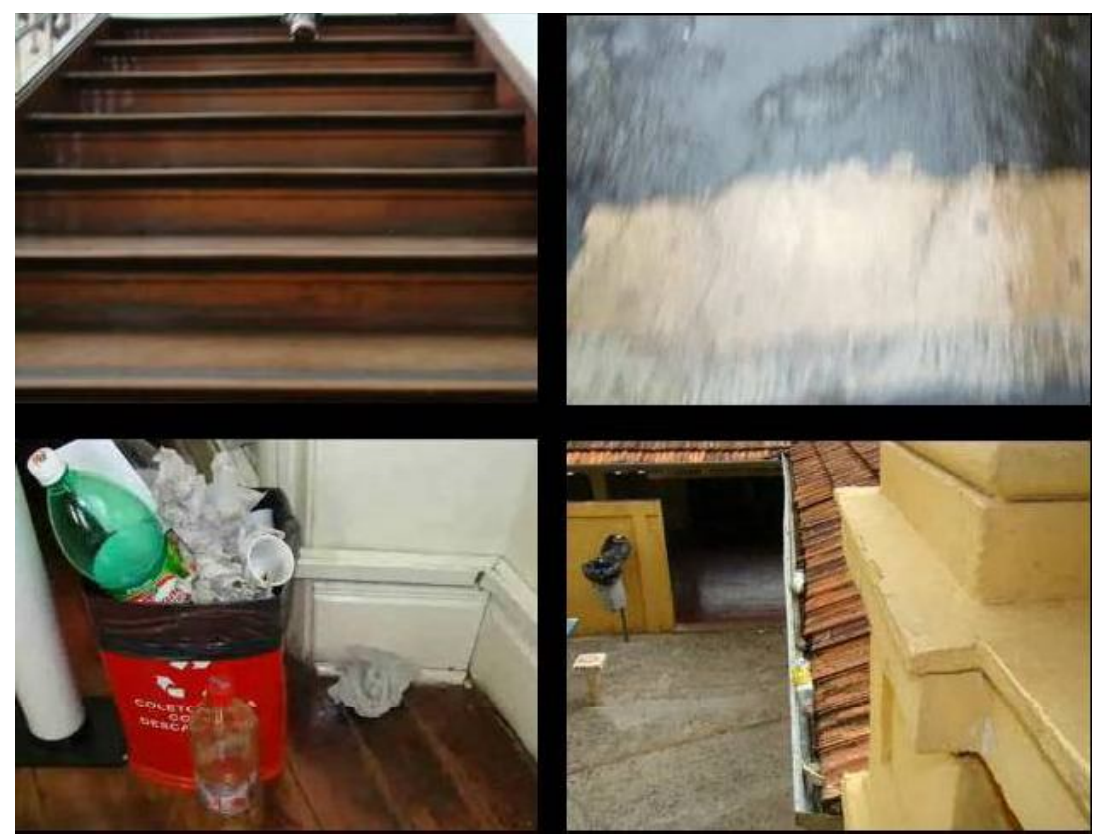

Figura 5 - Imagens paralisadas do vídeo ${ }^{12}$ disponível em http://vimeo.com/3159001.

10 Maria do Carmo B. Barros, Ricardo de U. Moura, Barbara M. Teixeira, Clóvis M. Neves e Danilo de O. Pessoa.

11 A reportagem intitulada "Percepção ambiental é povoada de imagens-clichê" encontrase disponível em: http://www.comciencia.br/comciencia/handler.php?section=3 \&noticia=521. Acesso em: 23 jun. 2011.

12 Acesso em 23 jun. 2011. No endereço indicado podem ser encontrados outros vídeos produzidos durante o projeto "Educação, ciências e culturas: territórios em fronteiras no Programa Biota-Fapesp”. 
Imagens em movimento ${ }^{12}$ paralisadas. Atravessamentos por fragmentos e descontinuidades da escola, dos caminhos, dos corpos, do lixo. Aberturas e brechas na expectativa de que as imagens, clichês ou não, sejam potências para novos pensamentos e conhecimentos.

Invenções em filmes, documentários, livros didáticos e paradidáticos, sites, portais (educacionais ou não) que parecem já estar prontos com suas imagens, textos, intenções. Milagres da clonagem, Sr. DNA, padrões, cientistas. Comumente as imagens têm assumido um "fardo": explicação, ilustração, informação, como um complemento às palavras. Mas eis que alguns cientistas ou divulgadores de ciência resolvem deixá-las fugir dessas prisões e dessas funções, como mostra o breve trecho da entrevista que se segue.

Nesse projeto que eu comecei a ter o contato com Mata Atlântica e começar a trabalhar nesse universo de uma mata sem trilha, de começar a abrir trilhas e tudo mais; foi a minha grande escola, de começar a aprender a enxergar aquilo de uma maneira... de certa forma diferente do que você vê descrito nos livros. Porque eu fui para lá sem grandes embasamentos teóricos de todas essas teorias mirabolantes que a gente vê por aí e isso de certa forma foi bom porque eu não fui viciado para lá... A seqüência de imagens que eu posso te passar... são os caminhos das cem Matas Atlânticas que eu acabei percorrendo (SPEGLICH, 2009, p. 100).

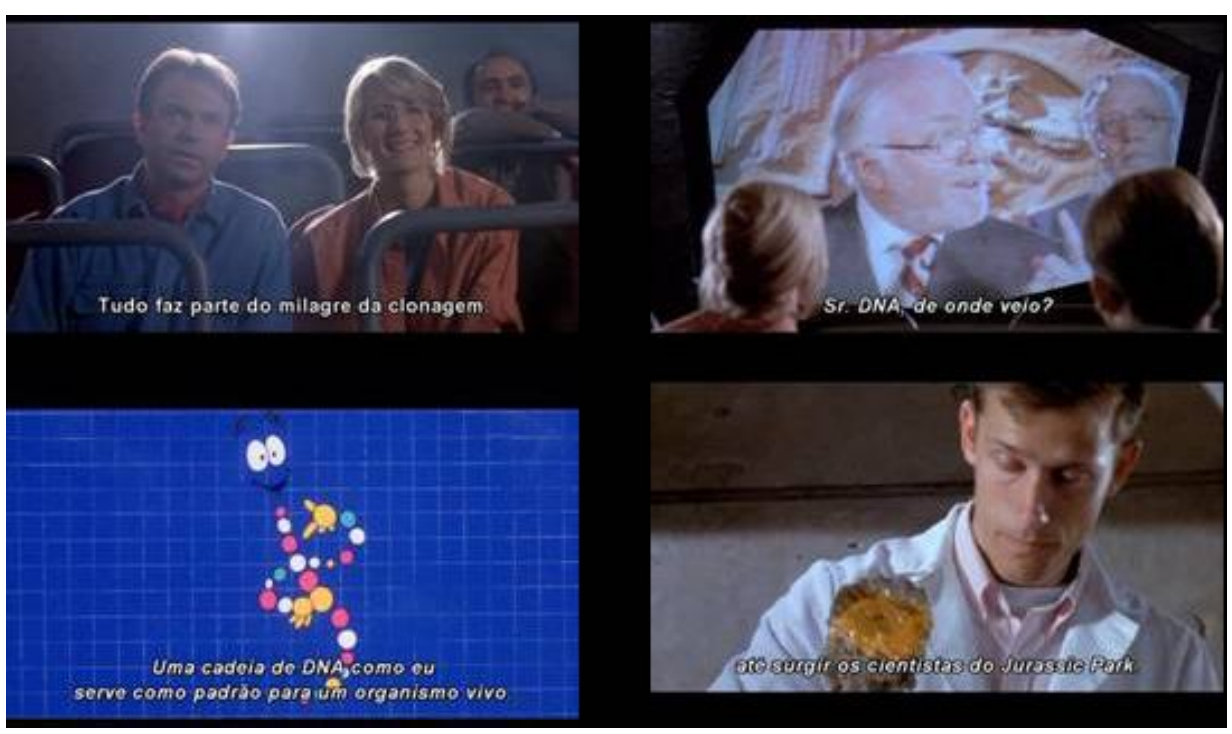

Figura 6 - Imagens extraídas da produção cinematográfica de Jurassic Park (1993), dirigida por Steven Spielberg. 
Ao ser perguntado sobre uma imagem de sua pesquisa, Pedro Luís Rodrigues de Moraes $^{13}$ primeiramente se propõe a mostrar os "géis": imagens resultantes de testes em enzimas utilizados para verificar herança genética e, assim, demarcar as possibilidades de parentesco entre as populações e indivíduos das plantas estudadas (SPEGLICH, 2009). Ainda junto à autora, acompanhamos Pedro de Moraes mudar de ideia e escolher outra imagem que não os géis para expressar sua pesquisa: "os caminhos das cem Matas Atlânticas" percorridas por ele ao longo de seu trabalho. Caminhos que se abrem em matas fechadas, que abrem o olhar e o pensamento para estarem nos lugares sem predeterminações de teorias. As cem Matas Atlânticas puderam ser percorridas exatamente por não terem um referencial predeterminado do que deveria ser visto ou pensado. Matas Atlânticas que estavam libertas da necessidade de se assemelharem às teorias e conceituações, de comunicarem dados ao pesquisador que estaria ali apenas para coletá-los. Matas Atlânticas que foram abertas, percorridas, criadas. Fugas na invenção do pesquisador. Criação de vida na multiplicidade da singularidade do ambiente da Mata Atlântica. Cem delas e não sem ela.

Imagens acompanhadas dessas cem Matas Atlânticas como "um bloco de devires e de sensações", nas palavras de Christine Buci-Glucksmann (2007, p. 70), não comunicando resultados do trabalho, não representando lugares, não ilustrando espécies, não dissecando a metodologia de pesquisa. Imagens que nos levam a extremos: o invisível, o indizível, o impensável... criando um intervalo, um entre imagem do qual podem emergir movimentos para o pensamento. Movimentos em fuga das representações, do registro, da comunicação, da ilustração. Cartas caóticas que vêm e vão. Viajam. Convidam...

[...] Viajar é [...] permitir que a força do inesperado nos arrebate. [...] Seja para se sentir no exílio ou em um novo reino, viajar é sempre ocasião de descoberta e pressupõe o estado de espírito de quem tem vontade de não ter mais vontade, de entregar-se ao acaso (FEITOSA, 2006, p. 279-280).

\section{Convites}

Este texto deixa convites. Subam nas estruturas e sintam o cheiro que não exala e o suor que não escorre e a poeira que não levanta. Convites a fugas, a explicações, a pensamentos. Deixamos aqui um breve convite ao devaneio. Convites também a esquecimentos, a nos perdermos entre imagens e sentidos. Percam-se no poente, nas luzes cor de laranja que envolvem as maçãs do rosto e escondem os olhares curiosos que fitam o inusitado. Convites a esquecimentos: das representações, das significações, do tempo cronológico. Palavras não ditas continuarão a vagar quando a noite chegar. Convites a provocar pensamentos, escritas, pesquisas,

13 Professor do Instituto de Biociências, Departamento de Botânica, da Unesp de Rio Claro, Pedro L. R. de Moraes foi entrevistado por Érica Speglich durante seus estudos de doutorado. 
vidas vinculadas a seus limites e suas margens. Porém, brancos. Convite ao desejo, um desejo de criar, (n)o entendimento de que seria na instalação da possibilidade de devir que se instalaria a possibilidade de vida. De escrita e pesquisa. Caminhe por entre os montes e toque os pássaros que teimam em aparecer. Convite a olhar para os ambientes como invenções: ambientes fabulados. Aqui, por imagens. Porém, visíveis. Sentidos. Convite a uma dispersão das fixações, em movimentos por outros pensamentos para a educação ambiental em fugas pelas frestas, criativamente em fabulações $e$ proliferações de ambientes, ciências, mundos, sentidos. Mergulhem no choque de cores e texturas que não explicam e fazem com que o incompreensível pule. Convite às questões: que vidas e que ambientes se inventam nesses movimentos? Que educação ambiental se inventaria nesses encontros? E continue incompreensível. Porém, sentido. Expresso. E, com isso, a possibilidade de nos instalarmos, em devir. Porém.

\section{Referências}

AMORIM, Antonio C. R. de. MULPLICimagens (Folder). Seminário realizado pelo Projeto de Pesquisa "Educação, Ciências e Culturas: territórios em fronteiras no Programa Biota-Fapesp" e Grupo de Estudos 'Humor Aquoso', Faculdade de Educação, UNICAM, Campinas, São Paulo, 2009.

ANDRADE, Elenise C. P. de; SPEGLICH, Érica. Design? Desire? Dessin? Images resound... Texto apresentado no "The Deleuzian Event", organizado por Deleuze Studies, Institute of Humanities and Social Science Research, Manchester Metropolitan University, Manchester, UK, agosto de 2007.

- (Em)tornando o tempo n(d)o caldo em "c": cultura, cinema, ciência, centralidades. In: SIMPÓSIO INTERNACIONAL DE EDUCAÇÃO E FILOSOFIA, 2., 2008, Marília. Anais... CD-ROM.

BELLOUR, Raymond. Entre-imagens: Foto, cinema, vídeo. Tradução de Luciana A. Penna. Campinas, São Paulo: Papirus, 1997.

BUCI-GLUCKSMANN, Christine. Variações sobre a imagem: estética e política. In:

LINS, Daniel (Org.). Nietzsche/ Deleuz̧e: imagem, literatura e educação. Rio de Janeiro: Forense Universitária; Fortaleza: Fundação de Cultura, Esporte e Turismo, 2007.

COUTO, Mia. Pensatempos - textos de opinião. Lisboa: Caminho, 2005.

DELEUZE, Gilles; GUATTARI, Félix. Kafka - por uma literatura menor. Tradução de Júlio Castañon Guimarães. Rio de Janeiro: Imago, 1977.

. Mil Platôs. Capitalismo e Esquizofrenia. Tradução de Aurélio Guerra Neto, Ana Lúcia de Oliveira, Lúcia Cláudia Leão e Suely Rolnik. Rio de Janeiro: Editora 34, 1996. (v. 3). 
DIAS, Souza. "Partir, evadir-se, traçar uma linha": Deleuze e a literatura. Educação, Porto Alegre/RS, ano XXX, n. 2 (62), p. 277-285, maio/ago. 2007. Disponível em: <http://redalyc.uaemex.mx/pdf/848/84806205.pdf>. Acesso em: 23 jun. 2011.

DIAS, Susana. Percepção ambiental é povoada de imagens-clichê. Laboratório de Estudos Avançados em Jornalismo da Unicamp, Universidade Estadual de Campinas, 10 de fevereiro de 2009. Disponível em: < http://www.labjor.unicamp.br/midiaciencia/ noticias.php3?id_article=666>. Acesso em: 23 jun. 2011.

. A natureza ex-posta: imagens que duram. Laboratório de Estudos Avançados em Jornalismo da Unicamp, Universidade Estadual de Campinas, 12 de dezembro de 2008. Disponível em: <http://www.labjor.unicamp.br/midiaciencia/article.php3?id_article= 661> Acesso em: 23 jun. 2011.

FEITOSA, Charles. Educação do filósofo através das viagens. In: FEITOSA, Charles; BARRENECHEA, Miguel A.; PINHEIRO, Paulo (Org.). Nietzsche e os gregos: arte, memória e educação - assim falou Nietzsche V. Petrópolis, Rio de Janeiro: DP\&A, 2006.

FURTADO, Sylvia B. B. Imagens que resistem. O intensivo no cinema de Aleksander Sokurov. 2007. Tese (Doutorado em Ciências Sociais) - Universidade Federal do Ceará, Fortaleza, 2007.

GALLO, Silvio. Filosofia e educação: pistas para um diálogo transversal. In: KOHAN, Walter O. (Org.). Ensino de filosofia. Belo Horizonte: Autêntica, 2002.

GODOY, Ana. A menor das ecologias. São Paulo: EDUSP, 2008.

PAIVA, Sílvia. O cinema de Kiarostami: imbricações entre ficcional e documental. Trabalho apresentado no Grupo de Trabalho "Comunicação e Linguagem" do I Encontro dos Programas de Pós-Graduação em Comunicação de Minas Gerais - I Ecomig, PUCMinas Gerais, Belo Horizonte, julho de 2008. Disponível em: < http://www.fafich. ufmg.br/ecomig/wp-content/uploads/2009/08/PAIVA_Silvia_de_Texto.pdf>. Acesso em: 23 jun. 2011.

PALHARINI, Luciana. Conhecimento disciplinar: (im)possibilidades do discurso sobre a problemática ambiental. Pesquisa em Educação Ambiental, v. 2, n. 2, 2007, p. 29-48. Disponível em: <http://www.revistasusp.sibi.usp.br/pdf/pea/v2n2/03.pdf>. Acesso em: 23 jun. 2011.

SCLIAR, Moacyr. A arte de escrever cartas. 20 de julho de 2003; Disponível em: <http://blocosonline.com.br/literatura/prosa/cl/artcart/ac030915.htm>. Acesso em: 23 jun. 2011.

SPEGLICH, Érica. Duração: entre imagens do Programa Biota/Fapesp. 2009. 136 f. Tese (Doutorado em Educação) - Faculdade de Educação, Universidade Estadual de Campinas, Campinas, 2009.

UOL ESPORTE. Técnico do Arsenal chama Messy de jogador de PlayStation. 6 de abril de 2010. Disponível em: <http://esporte.uol.com.br/futebol/campeonatos/liga-dos-campeoes/ ultimas-noticias/2010/04/06/tecnico-do-arsenal-chama-messi-de-jogador-deplaystation.jhtm>. Acesso em: 23 jun. 2011. 